\title{
EI Scale - an Environmental Impact Assessment Scale Related to the Construction Materials Used in the Reinforced Concrete
}

\author{
Gilson Morales*, Antonio Edésio Jungles, Sheila Elisa Scheidemantel Klein and Juliana \\ Guarda \\ Universidade Federal de Santa Catarina; Rua João Pio Duarte Silva, s/n; C. P.: 476; 88040-970; Florianópolis - \\ SC - Brasil
}

\begin{abstract}
This study aimed to create EI Scal, an environmental impact assessment scal, related to construction materials used in the reinforced concrete structure production. The main reason for that was based on the need to classify the environmental impact levels through indicators to assess the damage level process. The scale allowed converting information to estimate the environmental impact caused. Indicators were defined trough the requirements and classification criteria of impact aspects considering the eco-design theory. Moreover, the scale allowed classifying the materials and processes environmental impact through four score categories which resulted in a single final impact score. It was concluded that the EI scale could be cheap, accessible, and relevant tool for environmental impact controlling and reduction, allowing the planning and material specification to minimize the construction negative effects caused in the environment.
\end{abstract}

Key words: environmental impact, eco-design, reinforced concrete production, construction

\section{INTRODUCTION}

Studies on the environmental impact level caused by the use of construction materials during the concrete structures production.have presented a theory for reconstructuring problem solving and expertise acquisition by derivacional analysis (Carbonell, 1994). Material performance considering its environmental impact has been classified as low and high. Thus, it was defined as an interval according to the damage level registered between the opposite extremes caused by the construction enterprise. The study to create this scale is related to the need on classifying the environmental impact levels caused by the materials used in the construction, but it does not include the impacts which occurred during their industrial production.

EI-scale indicators allow evaluating the environmental impact damage level towards the ecosystem and analyze the materials used in concrete structures. It is difficult to evaluate the environmental impact level caused by a construction process by the tools such as life cycle assessment, or material flow. Materials environmental impact potential could be evaluated; however, this impact can be measured through the attribution of position relevance levels using a

*Author for correspondence: gmorales@uel.br 
scale. The scale must establish damage points through the reference requirements/criteria and should be based on normalized information of research results. According to Babbie (1997), a scale is considered reliable taking into consideration its order criteria, when it identifies the structures within the indicators, presenting different variables intensities.

Inherent aspects of most important items which express the environmental impact caused by the materials used in the scale creation process are presented as follows. The study of the areas such as the procurement, specification, application, development, performance and evaluation of all materials used in the construction and civil engineering are very important. Coverage is also provided of the aspects which need to be taken into account when selecting the materials, including embodied energy, environmental impact, service life, refurbishment, recycling and reuse (ICE, 2007).

To estimate the damage level of material extraction, it is necessary to know the resource characteristics. The resource renovation capacity may or may not contribute favorably to the extraction impacts. In the present work material were classified into five categories: non-renewable resource, difficult renewable resources, normally renewable resources, easy renewable resource, nonscarce resource. A non-renewable resource is the one which does not allow the replacement of the material. A difficult renewable resource is the one in which the material replacement could occur in a long period of time, such as a century, or longer. A normally renewable resource allows the material replacement within 50 years, and an easy renewable resource allows it within 10 years. A non-scarce resource does not present any depletion risk.

The construction industry is one of the most natural resources consumers. Cement, lime, and aggregate industries are the main suppliers. (Brezer, Han et al., 1996). In Brazil, a large amount of sand production comes from the rivers drainage. This extraction impacts the environment in many different ways: rivers natural shape, edges erosion, sediment deposition, flood, aquatic life damage, vegetal cover depletion, etc. The growing sand consumption in Brazil has caused resources depletion near urban centers. The public policies for environmental protection and its high consumption have caused progressive cost elevation. There is a tendency in Europe and
U.S.A. for substituting the natural sand by another kind of gravel.

Stone crushing process generates a high dusty material and its residue must pass through washing processes. This process removes the materials with diameter of $0,075 \mathrm{~mm}$ or less, which can pass through the sieve (200 mesh), according to ABNT proceedings (Brazilian Association of Technical Norms).

According to Morales (2006), stone crushing process involved in the aggregates production generates 15 to $20 \%$ of material with less than 75 micrometers. These fine particles are inadequate to be used as sand in structural concrete and must be removed. Its disposal impacts aquatic life and water bodies, causing the rivers deposition, high turbidity, and human health. This material remains in water bodies surface affects the photosynthesis process due to the low- light penetration. Generally, 3\% of this fine material remains suspended in the air and/or diluted in the water. Particles with dimensions of less than 2.5 micrometers are harmful for humans and cause respiratory problems. They can also affect the vegetation as it sticks on plants surface, affecting natural activities, gases exchanges, and mineral absorption. Moreover, explotation sites will require recuperation actions. The contaminant emissions during the production of construction materials pose environmental risks, considering $\mathrm{CO}_{2}$, dioxine, and other gases emissions. Generally, actions related to $\mathrm{CO}_{2}$ emission control are not taken.

\section{Co-processing emissions}

During co-processing, mainly during the industrial co-incineration, the waste is considered a complex problem. The waste can be dangerous to the neighborhood when is incinerated, or transported. Besides, industrial co-processing can issue heavy metals. Silva (1999) mentioed that co-processing was considered a low risk process highlighting that any kind of waste incineration contributed to the chemical compounds emission, from which only dioxins, heavy metals and mercury were known. All these compounds are recalcitrant and can be bio-accumulated so their total reduction is recommended.

Dioxin is a generic name given to chlorine and hydrocarbon compounds which are emitted during wood and pesticide production and incineration of certain plastic and tires. These substances are considered highly toxic and belong to the 
Recalcitrant Pollutants Group. They are related to toxic waste and internationally controlled by Basel Convention and Global PIC Agreement (this information and previous permission in case of international trading or transport).

To evaluate the co-processing effects towards the atmosphere, it is necessary to obtain the information about the product, as it is a coprocessed product with or without contaminants. In case of presenting heavy metals, they should be evaluated if they remained fixed in the cement matrix, or if they could be released to the nature. According to Siqueira (2002), heavy metals concentration within thr material flow during the processing could be determined by collecting and analyzing the samples.

Data is used to calculate a mass balance and determine metal distribution (\%) based on the retention of each process chain. Afterwards, the emission of each element is estimated and compared to emission patterns. The etopographic and meteorological data of emissios are applied in an atmosphere dispersion model, allowing to predict the metal concentration in the atmosphere to evaluate their impacts. Heavy metals are present high density, generally higher than $5 \mathrm{t} / \mathrm{m}^{3}$. Also, they have complex spectrum and colored salt formation with low electric potential and are anfoteric. These metals produce weak acid and base and can be considered oxidant agents, e.g., cadmium, lead, mercury and zinc. Silva (1999) discussed the use of oil burning process stating that there were another non-energetic recycling which could be used and mentioned that the best process to be used was the regeneration with less energy consumption.

Other wastes that can be co-processed in the cement production are the organic solvents originating from painting use and organic products. The interest of cement industries for these wastes is due to their high calorific capacity, and they are used to substitute the high cost combustibles, such as coal.

\section{Toxic gases emission}

Toxic gases emissions are responsible for increasing the green house effect and its consequent planet average temperature. Brazil is responsible for around $3 \%$ of those world emissions. Certain toxic compounds produced during the industrial processes may affect the air quality and cause health problems, respiratory diseases and many skin problems. The ozone layer is localized around 10 to $15 \mathrm{~km}$ away from the earth surface where the ozone concentration is higher. Recalcitrant organic pollutants once released to the atmosphere, are not easily degraded and get into the feeding chain easily. They can accumulate in animals adipose tissue and present different metabolism They are water insoluble and carcinogenic and cause irregular structure formation. They also affect the immunological, cardiovascular, hormonal, digestive, respiratory and reproductive systems.

Besides carbon dioxide, other emissions can contribute to the ozone layer depletion. Biogas, rich in methane, is 21 times more harmful to the atmosphere than carbonic gas. Fossil combustible such as gasoline and diesel are highly toxic, affecting the air quality and contributing to the global warming process.

\section{Waste issues}

It is important to consider the aspects related to waste generation, transport, handling and material application. Thus, the material choice will be related to its waste generation and characteristics as recycling, possibility of using it during the production of another material or reuse.

In construction, the resource choice is a relevant aspect, considering that its characteristics may affect the final disposal of the material. For instance, amiant cement is highly toxic for humans and environment. According to Luízio and Ferrão (2005), the waste management belongs to the industrial ecology directed by an association related to the product life cycle assessment. Thus, it is possible to know in what phase the waste was originated and incorporate it during the production process of another material. This should be an integrated approach considering economical and environmental issues.

Recyclability is the potential material and/or product capacity for returning to the production cycle, or other uses may originate new materials and products. In the present work, three levels to determine the waste recyclability were defined: easy-recycling waste, medium-recycling waste, difficult-recycling waste. An integrated approach is needed to consider materials life cycle and lifetime. Recycled materials may be incorporated during the production of other products. If some contaminants as heavy metals are incorporated during some kind of cement production, the producer is responsible for this phase management. Therefore, producers must provide recycling, or reuse alternatives in the 
end of products lifetime. It usually occurs during the fluorescent lights production; thus, this kind of management is considered sustainable. According to Marinho (2001), it is not advisable to invest in the pollutants dilution due to its inefficient way to minimize the pollution problems. Each waste requires adequate actions for specific problems. In some cases, it is necessary to keep/hold in the industry, but sometimes recycling and waste reuse are possible actions. However, it must be classified through a scale which estimates its environmental impact. Moreover, synthetic products are not biodegradable, remaining in the environment for centuries. Almost all kind of waste produced during the resource life cycle are used by other organisms (Silva, 1999).

Angulo et al. (2005) highlighted the importance of waste recycling management. Some aspects as waste characteristics, technology adopted and energy consumption during the reuse process may become recycled materials even more impacting than produced waste. Other aspects to be considered during the recycling process include the need of other material incorporation during the recycling process, a secondary waste generation after recycling, recyclability and damage potential of recycled products in the end of its lifetime.

The biodegradability is the process which transforms the larger molecules in small molecular fragments with oxygen incorporation. This process breaks the hard and resistant biofilms and degrades the molecules, turning them into smaller ones. Heating, humidity and sun light (UV rays) contribute to start the degradation process which may be accelerated during the material handling. Biodegradation is defined as the partial decomposition of organic materials by the microorganisms as bacteria, fungus and algae which convert materials into biomass, carbon dioxide and water. Thus, biodegradability is the product capacity to be absorbed by the environment with out without biological agents. It usually happens within a short period of time, not causing significant environmental impacts.

Environmental impacts caused by the synthetic material are higher due to the fact that these kind of material present difficult degradability. For instance, plastic materials disposed in landfills take too long to be completely degraded and inhibit or delay waste degradability. Most of the plastic commonly used in packing processes are polyolefins - simple hydrocarbon crossed chains. These chains present high molecular weight compared to water and $\mathrm{CO}_{2}$. Other products based on hydrocarbons are combustibles, such as gasoline and diesel oil. These compounds are water insoluble and can not be hydrated.

Plastic products may be designed to be degradable, so it is necessary to modify their chemical structures. Thus, they may be degraded under specific environmental conditions by the microorganisms. During this process, the microorganisms use materials as feed and energy source. Hydrocarbons and poliofine chains are excellent sources; however, they present two disavantages: microorganisms associated to the biological processes act in liquid medium; polymeric chains are still large to be consumed by the microorganisms and do not present oxygen. Hence, these compounds must be reduced, absorb water and incorporate oxygen in its structure. It is known that poliofines react slowly with oxygen, breaking the polymeric chains into smaller fragments which can be humidified. Considering the traditional poliofines, this reaction is too slow and biodegradation process takes a long period of time.

During the oxidative process, the conditions of polymeric chains reduction are maintained until the occurrence of plastic degradation process. Oxidative reactions do not require water. However, hydro-biodegradable products need water to start the degradation process.

Calorific capacity is the heat amount provided to a specific substance mass $(\mathrm{kg})$ to increase the temperature.

\section{Impacts}

Acceptable noise limits established by the ABNT (NBR 10.151) according to the zone area and period (day/night) are as follows: farming areas (40/35 dBA), residential, scholar and hospital areas (50/45); mixed area tending to residential (55/50); mixed area tending to commercial and administrative (60/55); mixed area tending to recreation (65/55); industrial area (70/60). Special actions are recommended to attenuate the consequence of these activities, as cranes localization $10 \mathrm{~m}$ far away from the most silent streets considering the noise emitted by diesel engines and crane arms movement. Taking into consideration bench saws, they must be kept closed in acoustically isolated environment. Other activities which emit noises as storage room, steel cutting, metal folding, carpentry and concrete production must be located near the noisiest street 
avoiding new noise sources. This kind of operation should be planned to occur simultaneously in appropriate time (Andrade, 2004).

Durability is defined as the period which the material or product present satisfactory performance according to project maintenance and performance specifications. The longer is the products lifetime, the longer will be its contribution to the ecosystem due to the delay of using substitutes, reducing its production. As a consequence, the resource extraction taxes will decrease.

This article aims to create a scale to assess the environmental impact level caused by the use of construction materials during the concrete structures production. It represents the original information with considerable data reduction to obtain a final score that shows the global environmental impact from diverse items.

\section{MATERIALS AND METHODS}

The methodology adopted to define an environmental impact scale to evaluate the construction materials was divided into the following phases: identification of environmental impact aspects, indicators establishment, variables definition to determine the scale interval and qualifying the intervals.

\section{Environmental Impacts Significant Aspects}

Among the aspects focused in the environmental impact analysis produced by the materials and processes are: recyclability; components recuperation; components access; separability; biodegradability; durability; incorporation of recycled material; material resource; contaminants lacking; material availability in the nature; reduction in resource use; energy reduction during its extraction, production, recycling and transportation; waste incineration and reuse; certification, facility's components separation, waste generation, simple and practical design considering energy use during production, distribution and transportation; use of renewable energy resources; use of multifunctional, recycled and renewable materials, durable products, packages recycling, use of hazardous and water based substances, labor accident control.
Indicators establishment and variables definition to determine the scale interval

Variables indicators are determined considering the aspects of each evaluated item and showing different intensity levels. According to Babbie (1997), this intensity variation indicates the occurrence of a structure among items. Following this idea, an item which accepts a high intensity association probably accepts a lower intensity association. Therefore, Guttman scale was adopted for some items considering these as more difficult variables indicators than the others. The acceptance of a hard item implies on the acceptance of an easier one, justifying Guttman scale adoption.

Other items, instead of representing only a damage situation, indicate the amount of favorable or harmful activities. However, it does not mean the acceptance of previous associations; which indicates that it is not considered a perfect Guttman scale. For these items, the scaloning technique was adopted. It is possible to obtain an impact level 3 due to high carbon dioxide emission, as well as waste generation during more than one phase on material utilization, as transportation, management and application.

\section{Indicators selection}

The scale, called EIS was proposed through the indicators based on materials performance and on criteria and requirements of impacts aspects related to eco-design concepts. The objective was that these indicators converted the information to be used directly. For instance, it presented the air quality through the primary data which expressed the pollution average level within the determined interval. Regarding the scales interval, the following aspects were analyzed and established.

\section{Material natural resource}

Non-renewable resource

Difficult renewable resource

Normally renewable resource

Easily renewable resource

\section{Material natural reserves \\ Extinct reserve \\ Extinction process reserve \\ Limiting reserve \\ Abundant reserve}




\section{Extraction process}

Causes soil damages

Causes air pollution by toxic gases

Causes air pollution

Causes pollution by inhalable particles

Causes flora damages

Causes water bodies' contamination by toxic products

Causes water bodies' pollution by suspended dust

Causes water shades contamination

Causes fauna damages

Causes ozone layer depletion

Causes sonorous pollution

Prejudices surrounding urban centers

\section{Industrial process of material production}

Emits high $\mathrm{CO}_{2}$ concentration

Emits moderate $\mathrm{CO}_{2}$ concentration

Emits low $\mathrm{CO}_{2}$ concentration

Does not emit $\mathrm{CO}_{2}$

Toxic products emission during products life cycle

Emission occurs during single packing operation

Emission occurs during transportation

Emission occurs during material handling and application

Emission occurs during utilization

\section{Waste presence}

Generates waste during material production

Generates waste during material transport

Generates waste during material handling

Generates waste during material application

\section{Waste recyclability}

Recyclable waste

Recycled waste to produce another material

Reusable waste

Co-processable waste

\section{Selective collection}

Easy selection waste

Manual selective waste

Non-selective waste

\section{Biodegradability}

Highly biodegradable material

Partially biodegradable material

Low biodegradable material

Hardly biodegradable material
Calorific capacity

Low calorific capacity

Medium calorific capacity

High calorific capacity

\section{Combustibility}

High combustibility

Medium combustibility

Low combustibility

Mass balance $\left(\mathrm{kg} / \mathrm{m}^{3}\right)$

Low mass $\left(>2500 \mathrm{~kg} / \mathrm{m}^{3}\right)$

Medium mass $\left(>5\right.$ and $\left.\leq 2500 \mathrm{~kg} / \mathrm{m}^{3}\right)$

High mass $\left(\leq 500 \mathrm{~kg} / \mathrm{m}^{3}\right)$

\section{Energetic balance}

High energetic balance

Medium energetic balance

Low energetic balance

Sonorous environmental impact

Noise below acceptable limit $(\leq 40 \mathrm{~dB})$

Noise under acceptable limit $(>40$ and $\leq 60 \mathrm{~dB})$

Noise above acceptable limit ( $>60$ and $\leq 80 \mathrm{~dB}$ )

Not acceptable noise (> $80 \mathrm{~dB})$

\section{Durability}

Low durability $(\leq 4$ years)

Acceptable durability ( $>4$ and $\leq 10$ years)

Good durability ( $>10$ and $\leq 20$ years)

Great durability ( $>20$ years)

\section{Maintenance requirements \\ Inadequate $(\leq 6$ months) \\ Acceptable ( $>6$ months $\leq 5$ years $)$ \\ Satisfactory ( $>5$ and $\leq 10$ years) \\ Great (> 10 years)}

\section{EI Scale establishment}

Items selected as indicators of each variable were evaluated to estimate its intensity level, defining scores from 1 to 4 . Four intensity intervals, or four answer patterns were determined, which were called scale types and form a scale structure. Items which presented the disagreement and ambiguity were not considered. Items relation for scoring represented different production phases and the most important materials were used. These phases included: material resource, renewability conditions, environmental damages caused by its extinction, toxicity of the material production process, contaminants generation and incorporation, toxic products emission during 
production, packing, transportation, handling, application and use.

During the study, the eight most evident aspects involved in the analyzed process were selected: four positive effect aspects and four negative effect aspects. Positive effect aspects were material waste, recyclability, facility on setting storage and selective collection, durability and resources reserve.Negative effect aspects were material acquiring process, carbon dioxide emission during material production, waste generation.

\section{EI Scale}

1. Positive effect item

1.1 Material waste recyclability
a) Co-processable waste
b) Partially recyclable waste
c) Completely recyclable waste
d) Reusable waste
e) Does not fit within item above

1.2 Facility on setting storage and selective collecting
a) Non-selective waste
b) Hard selective waste
c) Easily-selective waste
d) Non-selectable waste
e) Does not fit within item above

\subsection{Durability}
a) Low durability
b) Acceptable durability
c) Good durability
d) Great durability
e) Does not fit within item above

\subsection{Resource reserves}

a) Non-renewable resource

b) Difficult renewable resource

c) Normally renewable resource

d) Easily renewable resource

1.5 Waste incorporation in the material production
a) Does not incorporate waste
b) Incorporates $5 \%$ of waste
1
c) Incorporates between 5 to $15 \%$ of waste 2
d) Incorporates 15 to $30 \%$ of waste 3
e) Incorporates above $30 \%$ of waste
4

\section{Negative effect items}

2.1 Material acquiring process

a) Damages soil structure and fertility $\quad-1$

b) Damages soil and causes air/sonorous pollution

c) Damages soil and causes air/sonorous pollution and prejudices local fauna / flora -3

d) Damages soil and causes air/sonorous pollution and prejudices local fauna and flora and contaminates water bodies and water shades $-4$

e) Does not fit within item above

\subsection{Losses during material handling}

a) Do not present losses during material handling

b) Present losses up to 5\%

c) Present losses between 5 and $10 \% \quad-2$

d) Present losses between 10 and 15\% -3

e) Present losses above 15\% -4

\subsection{Carbon dioxide emissions during material} production $\begin{array}{lr}\text { a) Emits } \mathrm{CO}_{2} \text { hardly } & -1 \\ \text { b) Emits low } \mathrm{CO}_{2} \text { concentration } & -2 \\ \text { c) Emits moderate } \mathrm{CO}_{2} \text { concentration } & -3 \\ \text { d) Emits high } \mathrm{CO}_{2} \text { concentration } & -4 \\ \text { e) Does not fit within item above } & 0\end{array}$

2.4 Waste generation

a) Waste generation during material production

b) Waste generation during material production and transportation

c) Waste generation during material production, transportation and storage d) Waste generation during all phases above and during its application

e) Does not fit within item above

\section{Qualifying the intervals}

Environmental Impact Conversion Scale

The positive and negative items values selected through the combinations in the EI Software resulted in a final score for each evaluated material. This score could be converted to a performance level, considering the environmental impact caused through the scale shown in Figure 1.

The addition of values obtained by multiplying the materials final score by its total mass divided by total concrete mass determines the global impact. The global impact was classified according to the global score scale, as shown in Figure 2. 


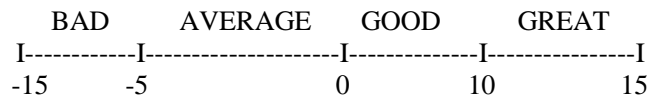

Figure1 - Performance material scale considering the environmental impact.

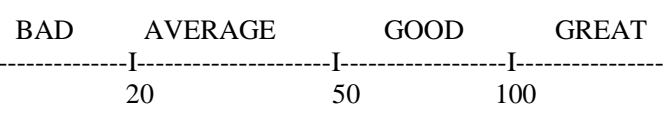

Figure 2 - Scale used to global impact determination

\section{RESULTS AND DISCUSSION}

The EI scale was created to be utilized through a computer program which consisted in a data base for planning, organizing, controlling and managing all the construction phases based on Case-BaseReasoning theory. This software was divided into three modules and one o them was used to identify the materials environmental impacts. This module kept the data which typified and characterized the materials environmental impact levels in the construction process. This was the most important module due to the establishment of similarities which intended to retrieve the stored similar cases in the data base. This scale provided an impact level according to some proceedings and recommendations which must be considered in the conformity evaluation process, taking into consideration environmental preservation.

Conformity evaluation of activities involved in the production process, proceedings, materials and other resources allowed keeping the product quality, guaranteeing losses reduction and waste generation, as well as assuring an environmentally correct execution.

The EI scale could be a cheap, accessible, and relevant tool for environmental impact controlling and reduction allowing planning and material specification to minimize construction negative effects caused in the environment.

\section{REFERENCES}

ABNT - Associação Brasileira de Normas Técnicas NBR 10.151. (2000); Avaliação de ruídos em áreas habitadas visando o conforto da comunidade. São Paulo

Ângulo; S.C.; Zordan; S. E.; John; V. M. (2005); Desenvolvimento Sustentável e a Reciclagem de
Resíduos na Construção Civil. PCC; EPUSP; São Paulo

Andrade; S. M. M.; Slama; J. G. and Azevedo; J. P. S. (2004); Metodologia para Avaliação do Impacto Ambiental Sonoro da Construção Civil no Meio Urbano. Revista Acústica; paper ID: 002/p.1; Guimarães; Portugal

Babbie; El. (1999); Métodos de Pesquisa de Survey; Editora UFMG; Belo Horizonte

Carbonell, J.G. (1994), Derivational Analogy: A theory of reconstructure problem solving and expertise acquisition. In Michalsky, J.S., Carboneel, J.G.[eds.] Machie learning - An Artifical InteliggeNCe Approach, Vol. II Morgan Kaufmann, 371-392.

Brezer, H et al. (1996), Promise Manual. Delft: University of Technology: Ratheneau Institut the Netherlands.

Ice Proceedings (2007), Construction Materials ISSN: 1747-650X, 160 (3), 1747-6518

Luízio; M. A. and Ferrão; P. C. (2004); Ecologia Industrial: ferramentas para a gestão de resíduos. IST-UTL; Lisboa

Marinho; M. B. (2001); Novas Relações Sistema Produtivo / Meio Ambiente - Do controle à prevenção da poluição. Dissertação de Mestrado em Engenharia Ambiental; UFBA; Salvador

Morales; G.; Jungles; A. E.; Klein; S. E. S.; Oliveira; R. R.; Pelepenko; G.; Guzi; D.; Guarda; J. (2006); Elementos Essenciais para a Análise da Produção de Estruturas de Concreto pelo Planejamento baseado em Casos integrando os Princípios do Eco-design. Paper presented at I International Congress on Design; Arts and New Technologies; 26-28 Oct; Lisbon

Siqueira; L. C. G. (2002); Avaliaçäo do impacto da emissöes de metais geradas no coprocessamento de resíduos em fábricas de cimento. Dissertação de Mestrado em Saúde Pública. Departamento de Saúde Ambiental; USP; São Paulo

Silva; M. O. (1999); Co-incineração em Cimenteiras. Paper presented at Associação PRO URBE e pela QUERCUS na Câmara Municipal de Coimbra.

Received: July 16, 2007; Revised: August 06, 2009; Accepted: August 23, 2010. 